\title{
Roadmap for Modeling RhPt/Pt(111) Catalytic
}

\section{Surfaces}

\author{
Jian Zheng, ${ }^{1} \neq$ Oleksii Ivashenko, ${ }^{1} \neq$ Helmer Fjellvåg, ${ }^{1}$ Irene M. N. Groot, ${ }^{2}$ Anja O. Sjåstad ${ }^{1}$ \\ ${ }^{1}$ Centre for Materials Science and Nanotechnology, Department of Chemistry, University of \\ Oslo, P.O. Box 1033, 0315 Oslo, Norway \\ ${ }^{2}$ Leiden Institute of Chemistry, P.O. Box 9502, 2300 RA Leiden, the Netherlands
}

\begin{abstract}
PtRh alloys are used as versatile multipurpose catalysts for a number of industrial applications, including fertilizer production and ammonia slip catalysts for $\mathrm{NO}_{\mathrm{x}}$ abatement purposes. For the latter, ammonia is oxidized to nitrogen at intermediate temperatures. To optimize the PtRh alloyed catalysts and explain the role of $\mathrm{Pt}$ and $\mathrm{Rh}$ for future intermediate-temperature ammonia oxidation operando studies, we prepared a series of distinct RhPt model surfaces. We explore post-annealing and high-temperature deposition as two routes for preparation of surface alloys, and compare results with literature examples. Scanning tunneling microscopy and X-ray photoelectron spectroscopy provide detailed information on surface morphology and composition, and demonstrate excellent temperature stability of $\mathrm{RhPt} / \mathrm{Pt}(111)$ in the temperature range targeted for operando catalytic studies. A detailed roadmap summarizes preparation conditions to achieve a broad variety of surface structures.
\end{abstract}




\section{Introduction}

Bimetallic PtRh surfaces are of high importance in heterogeneous catalysis. For instance, rhodium-promoted platinum is essential in industrial high-temperature processes like the Ostwald (NO) and the Andrussow ( $\mathrm{HCN})$ processes, ${ }^{1}$ and likewise for intermediate-temperature catalytic oxidation of ammonia to nitrogen. In $\mathrm{NO}_{\mathrm{x}}$ abatement from exhaust (diesel) combustion engines ammonia (urea) is added to achieve selective catalytic reduction (SCR) with $\mathrm{N}_{2}$ as the desirable product. ${ }^{2}$ State of the art de- $\mathrm{NO}_{\mathrm{x}} \mathrm{V}_{2} \mathrm{O}_{5}-\mathrm{WO}_{3} / \mathrm{TiO}_{2}$ catalysts have an efficiency of $95 \%$ at $300-400$ ${ }^{\circ}$ C. ${ }^{3-5}$ However, SCR technologies with even better efficiency are in progress. One option is to add excess ammonia, which in turn requests a second catalyst downstream, i.e. an ammonia slip catalyst that selectively oxidizes residual ammonia to nitrogen at intermediate temperatures. ${ }^{6-7} \mathrm{We}$ have shown by means of fixed-bed catalyst performance experiments that supported Pt-, Rh- and bimetallic PtRh nanoparticles $\left(\mathrm{Pt}-\mathrm{Rh} / \mathrm{Al}_{2} \mathrm{O}_{3}\right)$ are well suited for ammonia oxidation at intermediate temperatures. ${ }^{8}$ In terms of activity and selectivity to nitrogen, the alloys show different behavior than the monometallic counterparts, $\mathrm{Pt}$ and $\mathrm{Rh} .{ }^{8}$ To the best of our knowledge, the underlying reasons for why the alloyed PtRh nanoparticles perform differently is unknown. Therefore, surface-sensitive experiments to correlate ammonia oxidation product selectivity with PtRh surface composition and structure are called for. In order to perform such studies, well-defined PtRh surfaces are a prerequisite. In this paper, we present a roadmap for the preparation and characterization of well-defined Pt-Rh model catalysts in terms of tailor-made surfaces.

According to the $\mathrm{Pt}-\mathrm{Rh}$ bulk phase diagram, ${ }^{9} \mathrm{Pt}$ and $\mathrm{Rh}$ (both being cubic closed packing, ccp) form a complete solid solution above $1033 \mathrm{~K}$. Below $1033 \mathrm{~K}$ it is proposed, but not confirmed experimentally, that the alloys decompose to a two-phase mixture according to the presence of an immiscibility dome, see ref. ${ }^{10}$ and references therein. Small-sized colloidally formed PtRh 
nanoparticles exhibit a complete solid solution when simultaneous reduction of the metal salt precursors is facilitated. ${ }^{11}$ Finally, in the case of PtRh surfaces, computational modeling suggests that $\mathrm{Rh}$ as solute in a Pt host has no tendency to segregate to the surface, whereas the Pt as solute has moderate tendency to segregate from a Rh host. ${ }^{12}$ Remarkably, the bulk $\mathrm{Pt}_{25} \mathrm{Rh}_{75}(110)$ crystal is shown to exhibit strong Pt enrichment of $84 \%$ at the surface. ${ }^{13}$

When it comes to PtRh surface alloys, no information is readily available in the literature. The deposition of metal atoms on metal single crystals as e.g. $\mathrm{Pt} / \mathrm{Pt}(111),{ }^{14} \mathrm{Rh} / \mathrm{Rh}(111),{ }^{15}$ $\mathrm{Ag} / \mathrm{Ag}(111),{ }^{16}$ and $\mathrm{Ru} / \mathrm{Pt}(111)^{17-18}$ exhibit similar epitaxial growth patterns, which we will describe through the $\mathrm{Pt} / \mathrm{Pt}(111)$ system. The morphology of the obtained Pt layer(s) depends strongly on the substrate temperature, ${ }^{19}$ presence of impurities ${ }^{20}$ and deposition rate. The mobility of $\mathrm{Pt}$ atoms on $\mathrm{Pt}(111)^{21}$ is controlled by a range of barriers for diffusion (terrace, corner, step, intra-layer diffusion) and dissociation (kink, step, dimer dissociation). ${ }^{22}$ Owing to the six-fold symmetry of an fcc(111) surface, the formation of a hexagon-like island with six-fold symmetry is expected. In such a hexagon-like island, two types of steps can be distinguished: A and B steps, exhibiting $<111>$ and $<100>$ microfacets, respectively ${ }^{23}$ Both experiments and DFT calculations show that the A and B steps have different free energies of formation and diffusion coefficients along and across the step. ${ }^{16,22-25}$ The consequence of this is that the island shape is extremely sensitive to deposition and annealing temperature. In particular, at lower temperatures one type of facets exhibits faster growth, favoring a corresponding triangular structure with three-fold symmetry. ${ }^{26}$ At ca. $500 \mathrm{~K}$, the diffusion coefficient along the two types of steps is equal, both steps advance at the same speed, resulting in an equilibrium hexagonal shape. ${ }^{26}$

Here we report the first study on the nucleation, growth, and alloying properties of nanostructured $\mathrm{RhPt} / \mathrm{Pt}(111)$ surfaces with a range of diverse morphologies suited for (operando) 
catalytic studies by means of near-ambient-pressure X-ray photoelectron spectroscopy (NAPXPS) and Reactor-scanning tunneling microscopy (STM) (see Figure S1). We explore two routes to obtain alloyed surfaces: post-annealing after room temperature deposition of $\mathrm{Rh}$ on $\mathrm{Pt}(111)$ and direct $\mathrm{Rh}$ deposition at higher temperature. We show that the obtained morphologies depend on the preparation method. Additionally, we investigate the temperature stability of the obtained model surfaces, which is of high relevance for systematic studies of catalyst performance.

\section{Experimental details}

The experiments were performed in two setups: an in-house built ReactorSTM at Leiden University $^{27}$ and a recently installed commercial ReactorSTM system (Leiden Probe Microscopy B.V., LPM) at the University of Oslo (UiO). The UiO machine is based on the previously reported Leiden ReactorSTM, ${ }^{27}$ and contains a preparation and an STM chamber, both with a base pressure of $\sim 1 \times 10^{-9}$ mbar. The preparation chamber allows flexible high-quality sample preparation via $\mathrm{Ar}^{+}$-sputtering (IQE 11-35, SPECS), vacuum annealing (up to $1300 \mathrm{~K}$ ), metal deposition through a four-pocket e-beam evaporator (EBE-4, SPECS), and three leak valves for gas co-feeding. Equipment for Auger electron spectroscopy and low-energy electron diffraction (ErLEED 3000D, SPECS) is integrated to evaluate sample purity and crystallinity. The STM chamber is housing an STM system that is capable of scanning from ultrahigh vacuum (UHV) to high pressure (up to 6 bar). The unique design is described in detail by Herbschleb et al. ${ }^{27}$

Sample preparation. A Pt(111) single crystal (99.999 \%; Surface Preparation Laboratory (SPL), the Netherlands) was cleaned in repetitive cycles of $\mathrm{Ar}^{+}$-sputtering with an energy of $1 \mathrm{kV}$ for $5 \mathrm{~min}$ followed by annealing at $1150 \mathrm{~K}$ in both $\mathrm{O}_{2}\left(10^{-6} \mathrm{mbar}, 5 \mathrm{~min}\right)$ and in UHV (5 min). Crystal quality in terms of cleanness, crystallinity, and flatness was verified by means of AES, LEED, and STM. Rhodium was subsequently deposited onto the $\operatorname{Pt}(111)$ single crystal using the 
e-beam evaporator. The depositions were done at ambient temperature and at selected temperatures in the range from 300 to $700 \mathrm{~K}$. Rh (99.9\%, Goodfellow) evaporation was conducted in UHV at a pressure less than $2 \times 10^{-9} \mathrm{mbar}$, using a flux of $0.05-0.08 \mathrm{ML} / \mathrm{min}$ for $4-15 \mathrm{~min}$, as estimated from STM images. Pt evaporation (99.95\%, Goodfellow) was conducted in UHV at a pressure below $2 \times 10^{-9} \mathrm{mbar}$, using a flux of $0.04 \mathrm{ML} / \mathrm{min}$ for $12 \mathrm{~min}$. For studies of the effect of postannealing, the sample was first prepared at room temperature (RT), then heated to selected temperatures between 400 and $1050 \mathrm{~K}$, kept at the targeted temperature for 5 min, cooled down to RT and investigated using STM.

XPS measurements. XPS analysis was carried out in the ReactorSTM system at Leiden University, which is equipped with a SPECS spectrometer. The monochromatic Al Ka X-rays $(1486.6 \mathrm{eV})$ source was oriented at $54^{\circ}$ from the surface normal and electron collection was done along the surface normal. The analyzer pass energy was $10 \mathrm{eV}$, dwell time $0.1 \mathrm{~s}$. XPS spectra were analyzed using the least-squares curve-fitting program Winspec. ${ }^{28}$ Binding energies are reported with an uncertainty of $\pm 0.1 \mathrm{eV}$ and referenced to the $\mathrm{Pt} 4 \mathrm{f}$ photoemission doublet centered at 71.2 $\mathrm{eV}$, originating from the substrate. Analysis of the $\mathrm{Rh} 3 \mathrm{~d}$ spectra included a Shirley baseline subtraction and fitting with a convolution of Gaussian and Lorentzian functions. STM images (not reported) were collected to ensure good correlation between the surfaces studied using XPS at Leiden University and STM at the ReactorSTM at UiO.

STM measurements. Scanning tunneling microscopy was conducted using cut $\mathrm{Pt}_{80} \mathrm{Ir}_{20} 0.25 \mathrm{~mm}$ diameter tips (Goodfellow). The CAMERA 4.3 software package developed at Leiden University was used for data recording..$^{29,30}$ Imaging was performed in constant current mode at a typical sample bias of $-0.5 \mathrm{~V}$ and a tunneling current of $0.1 \mathrm{nA}$. 
Particle analysis. Statistics on cluster density, coverage, and height of particles were obtained from STM images using the Gwyddion software package. ${ }^{31}$ The Rh surface coverage is reported as total amount of $\mathrm{Rh}$ contained in any of the $\mathrm{Rh}$ layers, and is estimated by measuring the projected area of the layers. The contribution of the first to third layer was estimated by marking grains with 0.22 and $0.44 \mathrm{~nm}$ thresholds, corresponding to heights of one or two atomic layers, respectively. ${ }^{31}$

\section{Results and discussion}

\section{Morphology of $\mathrm{Rh} / \mathrm{Pt}(111)$ as prepared at $300 \mathrm{~K}$}

A representative STM image of $0.50 \mathrm{ML}$ Rh deposited on $\mathrm{Pt}(111)$ at $300 \mathrm{~K}$ is shown in Figure 1a. Rh islands nucleate and grow on the Pt terraces and at the steps uniformly. As can be seen from the line profile (Figure $1 \mathrm{~b})$, the height of a $\mathrm{Rh}$ single layer $(0.22 \mathrm{~nm})$ almost coincides with the height of a Pt step $(0.23 \mathrm{~nm})$; i.e. the exact location of a (pure) Pt step is not readily distinguishable at RT. Most of the Rh islands are composed of two layers, sometimes with atoms also present in a third layer. In agreement with this, the height histogram (Figure 1c) has three peaks in intervals of $0.22 \mathrm{~nm}$, corresponding to the three Rh layers, indicating a 3-dimensional growth mode at room temperature. Similarly to $\mathrm{Pt} / \mathrm{Pt}(111),{ }^{14}$ the islands have a nearly triangular shape, pointing in the same direction for both layers, comprising a close packed stacking. We interpret the observation of $\mathrm{Rh}$ islands attached to the Pt steps as a possibility of elemental mixing already at $300 \mathrm{~K}$. Depending on the evaporation rate and duration, isolated islands, bridged triangular clusters (as in Figure 1) and networks were formed (see Figure 9). 

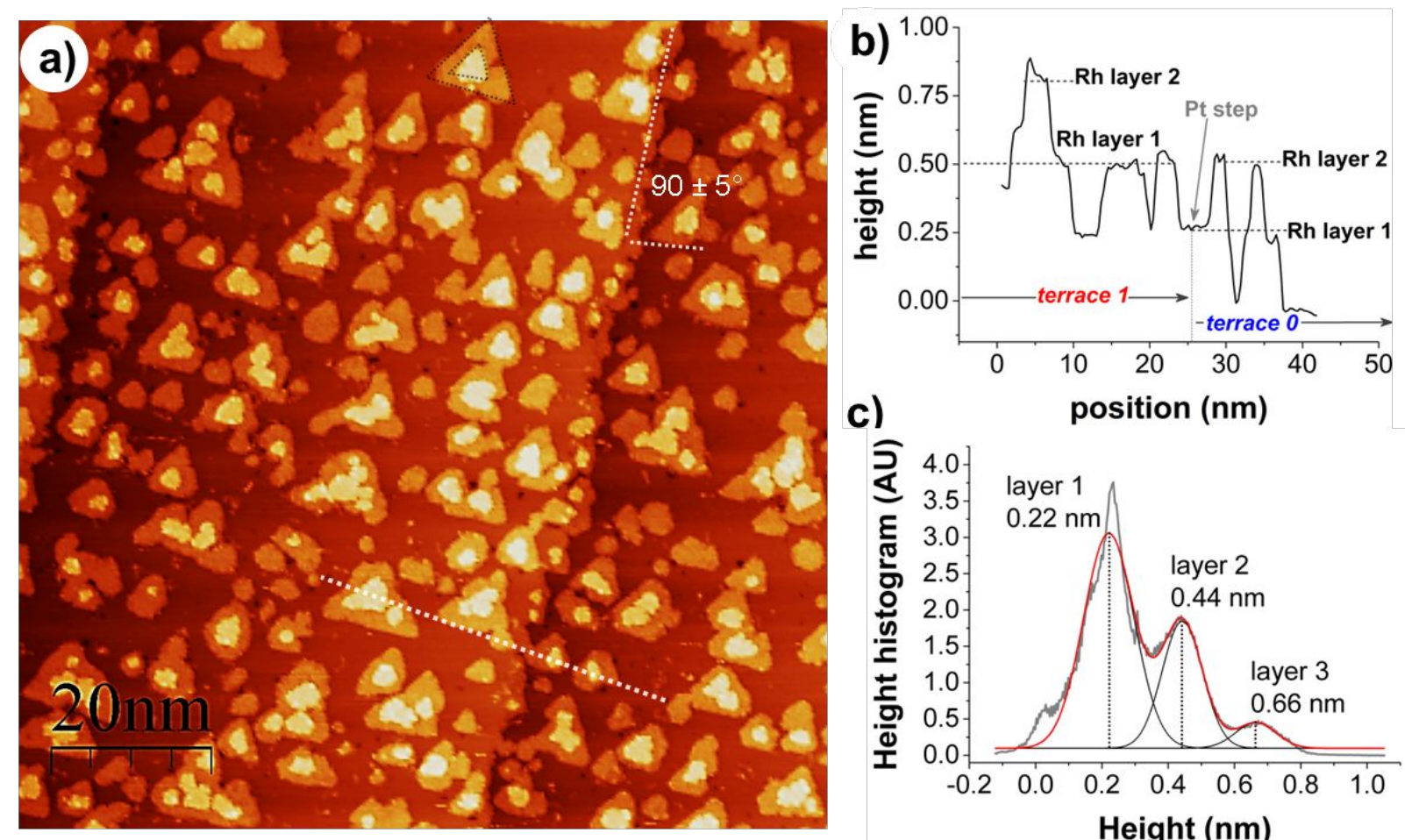

c)

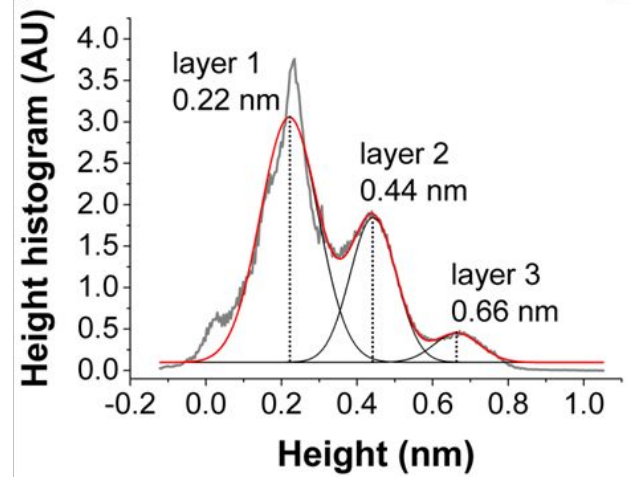

Figure 1. a) STM topography of $0.50 \mathrm{ML} \mathrm{Rh}$ on $\mathrm{Pt}(111)$ prepared at $300 \mathrm{~K}$, showing homogeneously distributed triangular Rh islands. Dotted line corresponds to the height profile in b). Image size $100 \times 100 \mathrm{~nm}^{2}, U_{b}-0.5 \mathrm{~V}, I_{t} 0.1 \mathrm{nA}$. b) Height profile across the Pt step with $\mathrm{Rh}$ islands composed of two layers. The approximate location of a Pt step between terraces 0 and 1 is indicated by an arrow. c) Height histogram showing the presence of three layers with individual height differences of $0.22 \mathrm{~nm}$, measured with respect to Pt terrace level.

\section{Morphology of post-annealed Rh-Pt/Pt(111) surfaces}

To mimic commercial and large-surface-area PtRh alloys, model catalyst surfaces ${ }^{32-36}$ with a high degree of $\mathrm{Rh}$ and $\mathrm{Pt}$ mixing are needed. However, for surfaces prepared at $300 \mathrm{~K}$, negligible mixing of Rh at the Pt steps occurs. Hence, to promote inter-diffusion of Pt and Rh at the top layers of the Pt(111) surface, we employed two strategies: i) deposition of $\mathrm{Rh}$ at $300 \mathrm{~K}$ followed by stepwise post-annealing up to $1050 \mathrm{~K}$; and ii) Rh deposition at elevated temperatures (up to 700 K). 
STM images of 0.50 ML Rh on Pt(111) post-annealed at selected temperatures between 450 and $750 \mathrm{~K}$ (Figure 2) show significant morphological changes. While annealing at $450 \mathrm{~K}$ enabled a minor growth of islands and healing of kinks, annealing at $550 \mathrm{~K}$ induced a drastic reshaping of the $\mathrm{Rh}$ triangles into hexagons, in which the second layer grew to cover the first one almost fully. Annealing to 650 and $750 \mathrm{~K}$ induced further growth and a flattening of the islands, i.e. the second layer decreased in size while adding more material to the first one. The faceting disappeared upon annealing to $900 \mathrm{~K}$, yielding randomly shaped scattered islands (Figure S2).
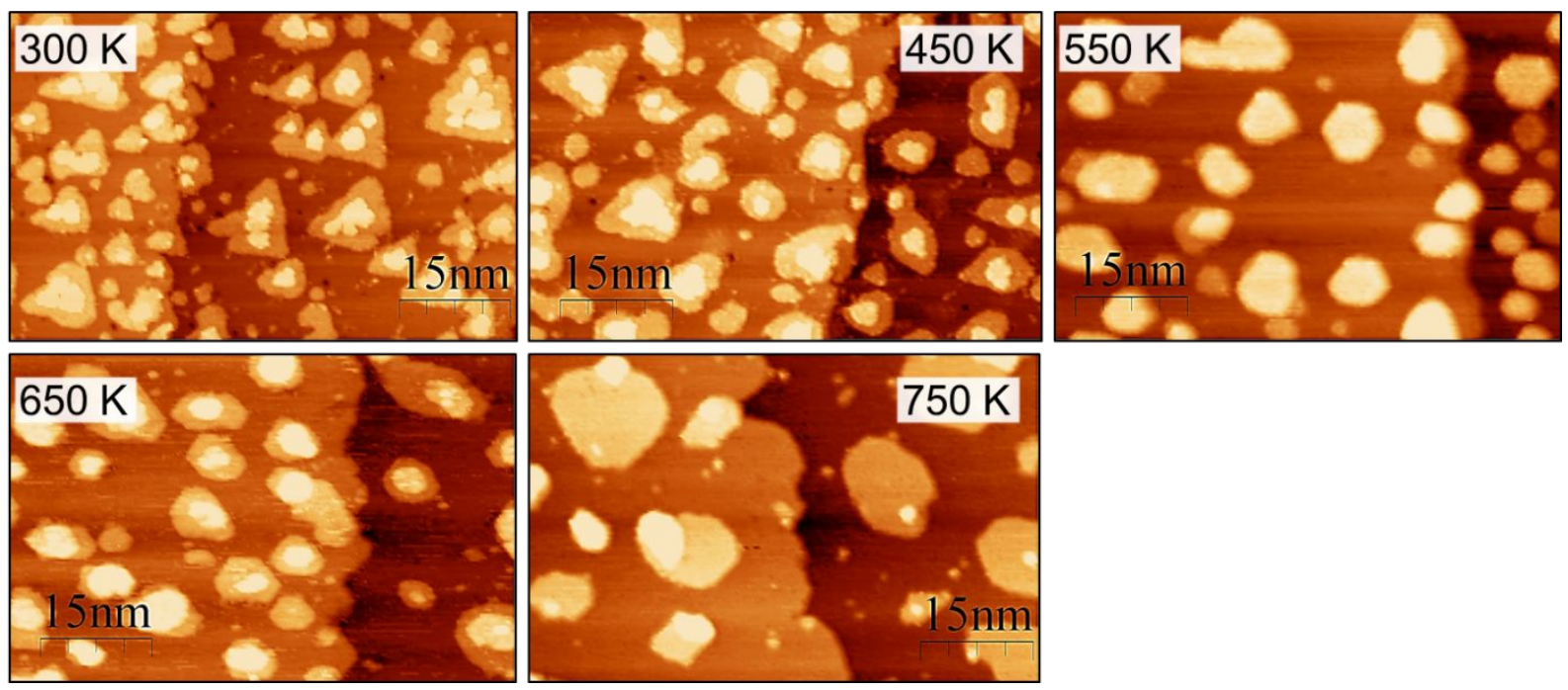

Figure 2. STM topography of 0.50 ML Rh on Pt(111) flash-annealed to 450 - $750 \mathrm{~K}$ and imaged at RT. Triangular clusters grow at $450 \mathrm{~K}$, and transform into hexagons by annealing at 550 - 650 $\mathrm{K}$. Larger single-layered islands are obtained at $750 \mathrm{~K}$. The initially straight Pt steps become roughened due to merging with $\mathrm{Rh}$ islands and subsequent alloying. All images are $67 \times 43 \mathrm{~nm}^{2}$, measured with $U_{b}-0.5 \mathrm{~V}, I_{t} 0.1 \mathrm{nA}$.

Statistical analysis of the data extracted from the STM images for 0.50 ML (Figure 2) and 0.92 ML (Figure S2) of $\mathrm{Rh}$ on $\mathrm{Pt}(111)$ describes the post-annealing process more quantitatively. The overall island density decreased from $3 \times 10^{12}$ to $0.63 \times 10^{12} \mathrm{~cm}^{-2}$ at $750 \mathrm{~K}$ (Figure 3). For the higher starting coverage of $0.92 \mathrm{ML}$ a similar trend is observed, where at $650 \mathrm{~K}$ islands merged into 
continuous Rh domains (Figure S2). Despite visible morphological changes during post-annealing of $\mathrm{Rh} / \mathrm{Pt}(111)$, the apparent coverage of $\mathrm{Rh}$ is relatively stable up to $900 \mathrm{~K}$ (Figure $3 \mathrm{~b}$ ). Specifically, the surfaces with 0.50 and $0.92 \mathrm{ML}$ coverage, respectively, at $750 \mathrm{~K}$ have lost only ca. $20 \%$ of their initial coverage due to subsurface diffusion. Notably, at and above $550 \mathrm{~K}, \mathrm{Rh}$ diffusion into the bulk can be accompanied by Pt diffusing towards the surface, compensating coverage loss. Thus the coverage estimated from STM may not directly represent the actual surface composition (see XPS and $\mathrm{Pt} / \mathrm{Pt}(111)$ results). In addition to interlayer diffusion, the fact that $\mathrm{Rh}$ islands merged with Pt steps is a strong signature of an increased tendency of mixing at elevated temperature.

The layer distribution within the islands varied with the annealing temperature (Figure 3c). For $0.50 \mathrm{ML} \mathrm{Rh} / \mathrm{Pt}(111)$ prepared at $300 \mathrm{~K}$, three layers are distinguishable with populations of 79, 19 and 2\%, respectively. At $550 \mathrm{~K}$ layer 2 increased two-fold, exhibiting its maximum proportion (38\%), correlating with a minimum for layer $1(62 \%)$. This suggests that upon annealing to 550 $\mathrm{K}$ interlayer diffusion of $\mathrm{Rh}$ occurs from layer 1 into layer 2, while subsequent annealing above $550 \mathrm{~K}$ drives $\mathrm{Rh}$ back into layer 1, which becomes the sole layer above $700 \mathrm{~K}$. The amount of $\mathrm{Rh}$ present in layer 3 can be neglected at post-annealing temperatures above $450 \mathrm{~K}$. A similar behavior is observed for the $0.92 \mathrm{ML}$ coverage, where two layers remain stable up to $550 \mathrm{~K}$ with gradual transition to single-layer morphology at higher temperatures.

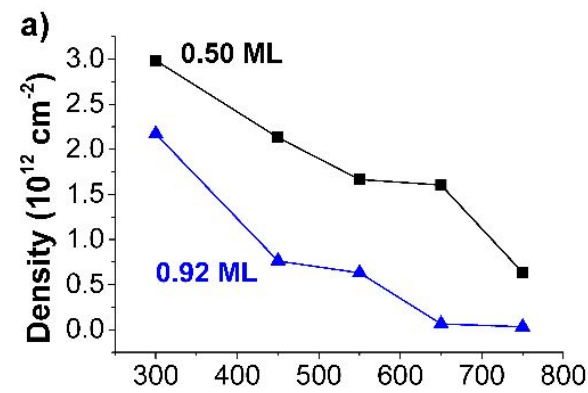

Annealing temperature $(\mathrm{K})$

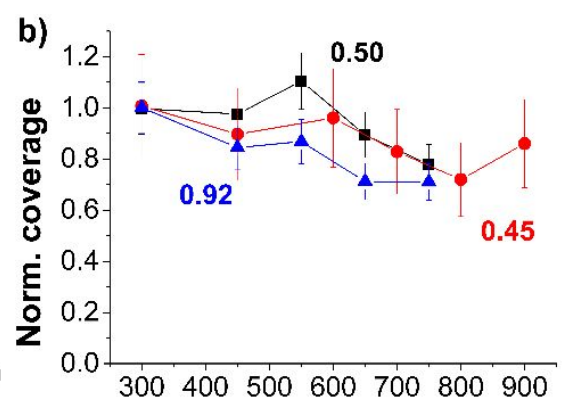

Annealing temperature $(\mathrm{K})$

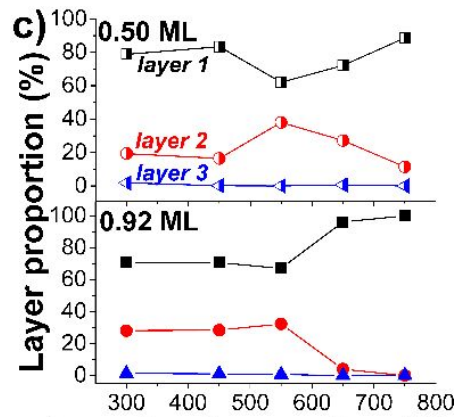

Annealing temperature (K) 
Figure 3. Island statistics as a function of post-annealing temperature estimated from STM images presented in Figure 2 and Figure S2 for 0.50 and $0.92 \mathrm{ML} \mathrm{Rh/Pt(111).} \mathrm{a)} \mathrm{Island} \mathrm{density;} \mathrm{b)}$ Coverage normalized to as-prepared value at $300 \mathrm{~K}$; c) Proportions of islands deconvoluted into three layers for 0.50 (top panel) and 0.92 ML (bottom panel) $\mathrm{Rh} / \mathrm{Pt}(111)$.

\section{Composition of post-annealed $\mathrm{Rh} / \operatorname{Pt}(111)$ surfaces}

To extract information on the actual surface composition and possibly induced changes due to post-annealing, XPS spectra were measured for $0.36,0.55$ and $1.00 \mathrm{ML} \mathrm{Rh} / \mathrm{Pt}(111)$ coverages stepwise flash-annealed up to $1050 \mathrm{~K}$.

For $1.00 \mathrm{ML}$ of $\mathrm{Rh} / \mathrm{Pt}(111)$ as prepared at $300 \mathrm{~K}$, the $\mathrm{Rh} 3 d_{5 / 2}$ core level was observed at 306.9 $\mathrm{eV},{ }^{36}$ with the $\mathrm{Rh} 3 \mathrm{~d}_{3 / 2}$ partially overlapping with the Pt $4 d_{5 / 2}$ peak at $314.2 \mathrm{eV}$ (Figure $4 \mathrm{a}$ ). For all coverages post-annealed up to $750 \mathrm{~K}$, the $\mathrm{Rh} 3 d_{5 / 2}$ binding energy was reproduced at $306.9 \mathrm{eV} \pm$ $0.1 \mathrm{eV}$ (Figure S6). To compare several coverages on the same scale we use the intensity ratio of the $\mathrm{Rh} 3 p_{3 / 2}(497 \mathrm{eV})$ and the $\mathrm{Pt} 4 f(71.1 \mathrm{eV})$ peaks, normalized to the starting $\mathrm{Rh} / \mathrm{Pt}$ ratio (Figure $4 \mathrm{~b})$. Annealing to $550 \mathrm{~K}$ led to less than $10 \%$ decrease in $\mathrm{Rh} / \mathrm{Pt}$ ratio, which can be rationalized either by $\mathrm{Rh}$ subsurface movement or by onset of $\mathrm{Pt}$ incorporation into $\mathrm{Rh}$ islands and thus $\mathrm{Pt}$ enrichment at the surface. The latter has been reported previously for $\mathrm{Ru} / \mathrm{Pt}(111)$ deposited at 523 $\mathrm{K} .{ }^{18}$ This process is further promoted by post-annealing to $750 \mathrm{~K}$, and results in an approximately $20 \%$ decrease in the $\mathrm{Rh} / \mathrm{Pt}$ ratio. Notably, after annealing to $750 \mathrm{~K}$, the STM-based coverage decreased by $25 \%$. Based on this substantial decrease in coverage we conclude that subsurface movement of Rh becomes highly relevant at and above $750 \mathrm{~K}$. Accordingly, with XPS we find a dramatic drop in the $\mathrm{Rh}$ signal for $0.55 \mathrm{ML}$ after annealing to 950 (32\% remains) and $1050 \mathrm{~K}$ (ca. $6 \%$ remains). 

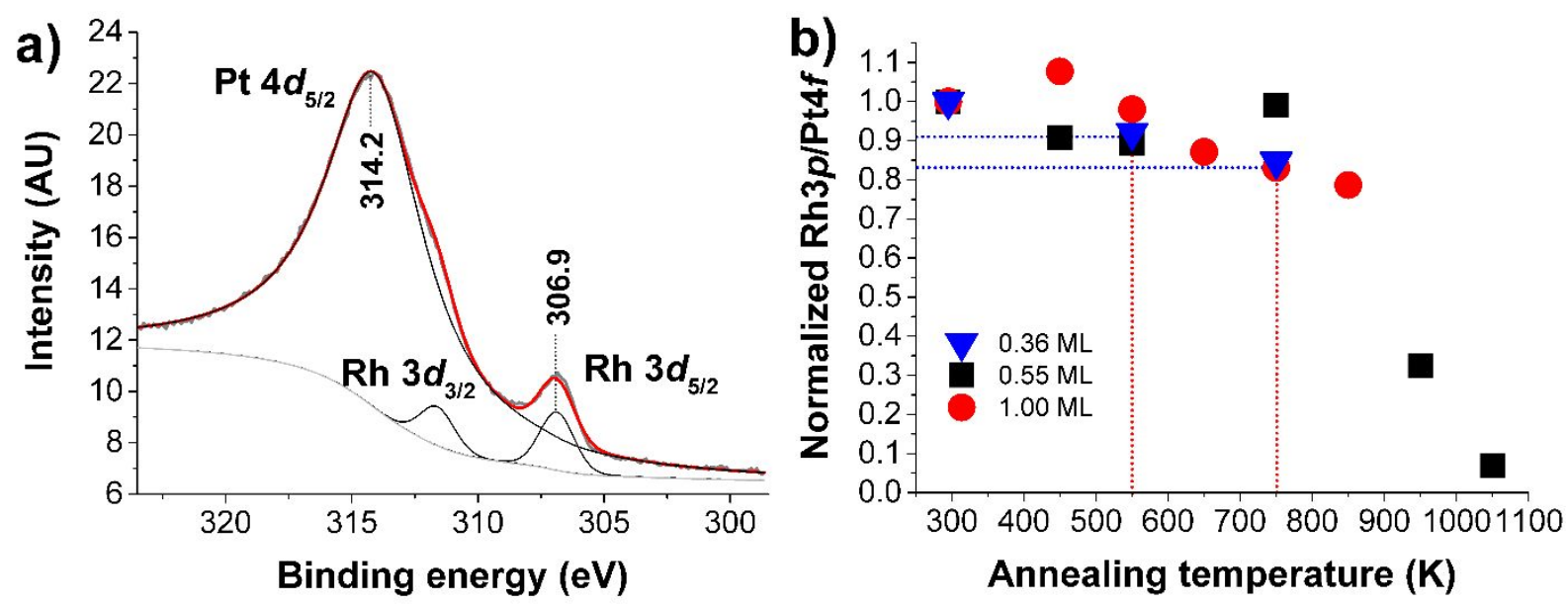

Figure 4. a) X-ray photoelectron spectrum of the $\mathrm{Pt} 4 d_{5 / 2}$ and $\mathrm{Rh} 3 d$ core levels for $1.00 \mathrm{ML}$ $\mathrm{Rh} / \mathrm{Pt}(111)$ prepared at $300 \mathrm{~K} . \mathrm{b})$ Normalized intensity ratio of the $\mathrm{Rh} 3 p_{3 / 2}$ peak centered at 497 $\mathrm{eV}$ and the $\mathrm{Pt} 4 f$ peak at $71.1 \mathrm{eV}$ as a function of post-annealing temperature for $0.35,0.55$ and 1.00 ML coverages, showing stability of the obtained Rh coverage up to $750 \mathrm{~K}$. Dataset for the sample with $0.55 \mathrm{ML} \mathrm{Rh/Pt(111)} \mathrm{(black} \mathrm{squares)} \mathrm{features} \mathrm{an} \mathrm{outlier} \mathrm{at} 750 \mathrm{~K}$, attributed to an instrumental factor. Parallel STM measurement showed a decrease in coverage from 0.55 ML to $0.45 \mathrm{ML}$, i.e. by $18 \%$, as seen for $0.36 \mathrm{ML}$ and $1.00 \mathrm{ML}$ samples.

When combining findings from STM and XPS, we conclude that around $550 \mathrm{~K}$ islands acquire an equilibrium hexagonal shape with a significant amount of $\mathrm{Rh}$ located in the second layer. This can be facilitated by the onset of Pt diffusion towards the surface, pushing Rh upwards into the second layer. Thereafter, at 550 - $600 \mathrm{~K}$ a partial enrichment of the surface with Pt occurs, leading to the formation of a surface alloy, which becomes substantial for surfaces annealed at $650-750$ $\mathrm{K}$. Thus, we chose to denote the surfaces annealed at and above $550 \mathrm{~K}$ not as $\mathrm{Rh} / \mathrm{Pt}(111)$ but as $\mathrm{RhPt} / \mathrm{Pt}(111)$. Our results are coherent with the studies of Ru and $\mathrm{Pt}$ on $\mathrm{Pt}(111)$, which used STM combined with AES to investigate mixing and alloying above $523 \mathrm{~K} .{ }^{18}$ 


\section{Stability of the $\mathrm{RhPt} / \mathrm{Pt}(111)$ surface at $550 \mathrm{~K}$}

It is a prerequisite that a tailor-made nanostructured surface morphology remain stable for the duration time of the operando experiment at relevant temperature conditions for the reaction in question. In this way, one ensures that any observed surface restructuring can be attributed to the presence of gases or adsorbed species. Keeping this in mind, a representative $0.68 \mathrm{ML} \mathrm{Rh/Pt}(111)$ surface was prepared at room temperature and flash-annealed at $600 \mathrm{~K}$ to promote the equilibrium hexagonal structure and mixing of Rh and Pt within the islands. The subsequent STM image of the $\mathrm{RhPt} / \mathrm{Pt}(111)$ surface after flash-annealing at $600 \mathrm{~K}$ and initial annealing at $550 \mathrm{~K}$ for $5 \mathrm{~min}$ is shown in Figure 5a, where multiple double-layered hexagons are visible. After additional annealing at $550 \mathrm{~K}$ for $2 \mathrm{~h}$ (Figure 5b), no significant changes in morphology were observed qualitatively.

To get more quantitative insight, we estimated the coverage after each annealing cycle (Figure 5c). Preparation of the surface using initial flash-annealing to $600 \mathrm{~K}$ decreased the $\mathrm{Rh}$ coverage from 0.68 to $0.60 \mathrm{ML}$, in line with the reduction in Rh surface coverage by $10-15 \%$ after annealing to $550-600 \mathrm{~K}$ as observed by STM and XPS, see Figure 3 and Figure 4. However, we note some minor differences for the surfaces extensively annealed to $500 \mathrm{~K}$ (STM images in Figure S4) and $550 \mathrm{~K}$ for $2-3 \mathrm{~h}$. Annealing to $500 \mathrm{~K}$ resulted in a minor decrease in surface coverage, while annealing to $550 \mathrm{~K}$ had no apparent effect or possibly a slight (+0.05 ML) increase in coverage after $3 \mathrm{~h}$. This result can be explained by more facile Pt embedding into $\mathrm{Rh}$ islands at $550 \mathrm{~K}$, compensating for minor Rh losses subsurface, as discussed earlier. Overall we conclude that $\mathrm{RhPt} / \mathrm{Pt}(111)$ does not undergo any significant structural and morphological transformations induced by temperature alone at $550-600 \mathrm{~K}$. However, compositional changes in the morphology cannot be ruled out. 

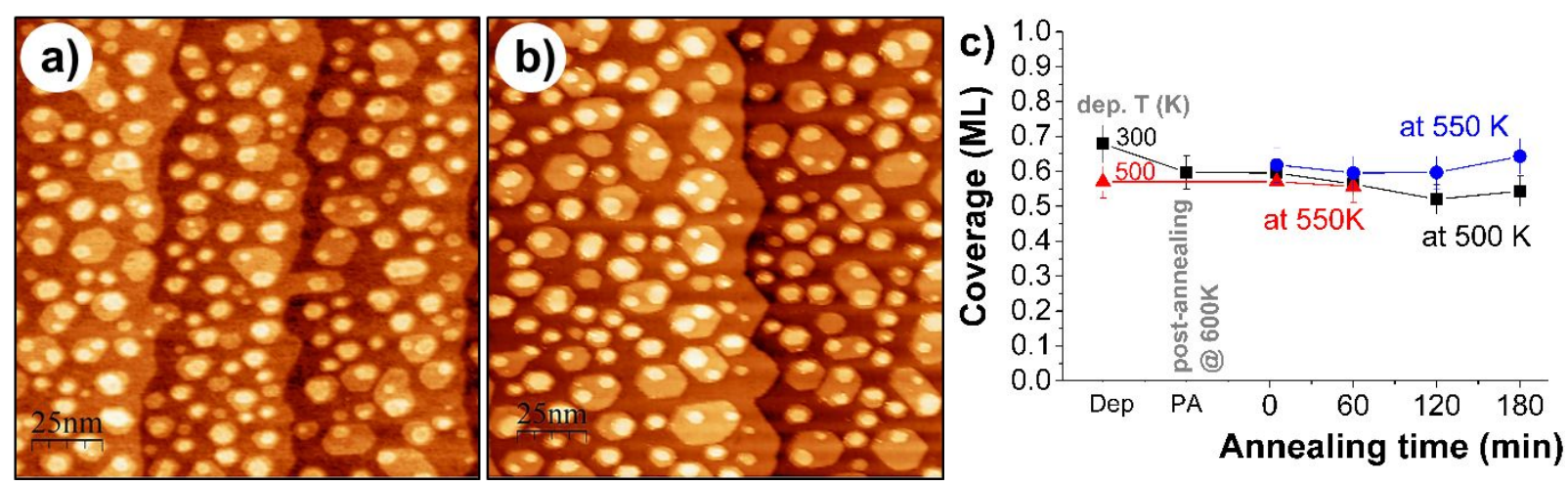

Figure 5. STM topography images of $\mathrm{RhPt} / \mathrm{Pt}(111)$ prepared at $300 \mathrm{~K}$, flash-annealed at $600 \mathrm{~K}$ and annealed at $550 \mathrm{~K}$ for $5 \mathrm{~min}$, i.e. before (a) and after (b) extensive heating for $2 \mathrm{~h}$ at $550 \mathrm{~K}$. $U_{b}$ $\left.-0.5 \mathrm{~V}, I_{t} 0.1 \mathrm{nA} . \mathrm{c}\right)$ Coverage as a function of surface treatment (based on STM). "Dep" and "PA" denote deposition at $300 \mathrm{~K}$ and flash annealing at $600 \mathrm{~K}$, respectively. Temperatures for the prolonged annealing are indicated on the graph. Coverage of the sample prepared at $500 \mathrm{~K}$, and heated at $550 \mathrm{~K}$ for $1 \mathrm{~h}$ is presented for comparison (red line).

\section{Rh deposition at higher temperatures}

To promote $\mathrm{Rh}$ and $\mathrm{Pt}$ mixing and surface alloying to form the $\mathrm{RhPt} / \mathrm{Pt}(111)$ surface, we explored direct deposition of $\mathrm{Rh}$ on $\mathrm{Pt}(111)$ at higher temperatures. 0.20 ML of Rh was deposited on $\mathrm{Pt}(111)$ kept at $400-700 \mathrm{~K}$ and imaged after cooling to RT (Figure 6). While the RT deposition of $0.20 \mathrm{ML} \mathrm{Rh}$ did not differ from that of $0.50 \mathrm{ML}$, deposition at $400 \mathrm{~K}$ yielded a mixed morphology composed of single-layered triangles, two-layered hexagons, and partially covered two-layered islands with some preference for step decoration. Depositions at 450 and $500 \mathrm{~K}$ resulted in formation of larger $(25 \mathrm{~nm})$ single- and double-layered triangles pointing in opposite directions (Figure S3). Interestingly, in this temperature range the tendency to nucleate at the Pt steps was further enhanced, manifested in formation of an elongated overlayer along the step. Small nuclei composed of a few atoms were observed in between the Rh islands (note the peak in island density at $450 \mathrm{~K}$ in Figure 7c). Deposition at $550 \mathrm{~K}$ produced single-layered compact 
triangles with sharp edges. At $600 \mathrm{~K}$ the islands were shaped into hexagons with slight preferential growth in one direction. At $700 \mathrm{~K}$ the STM topography showed an empty surface.

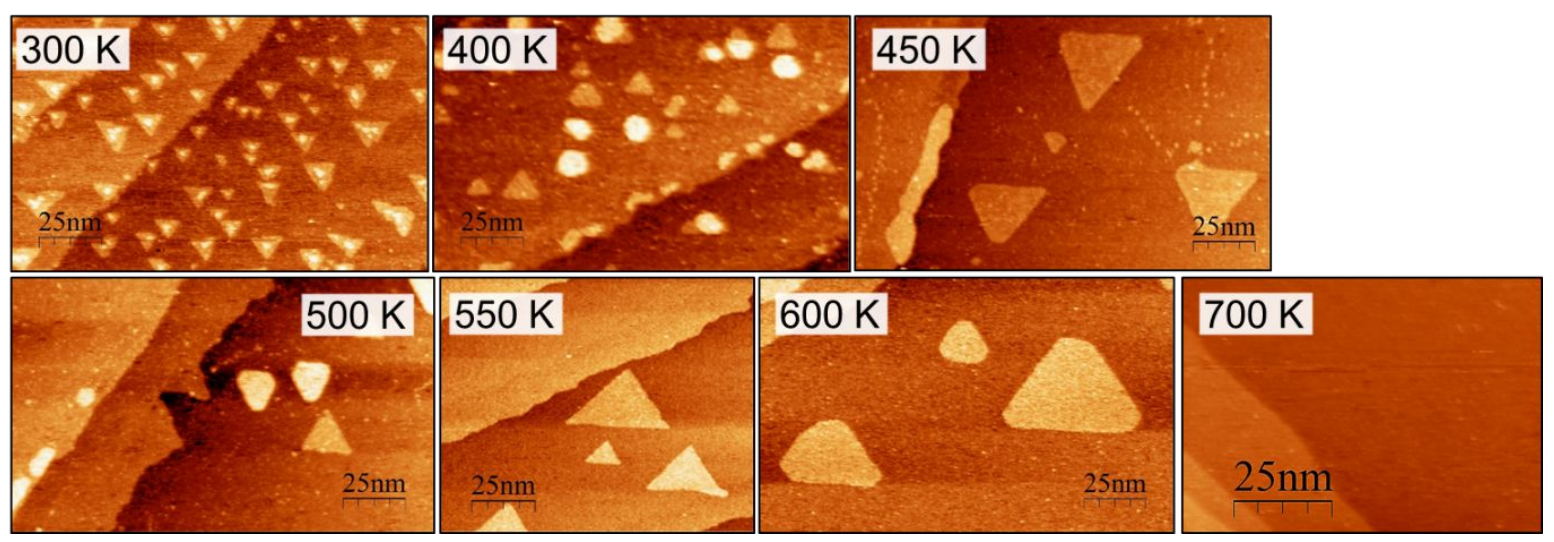

Figure 6. STM topography images of $0.20 \mathrm{ML}$ of $\mathrm{Rh}$ deposited on $\mathrm{Pt}(111)$ at $300-700 \mathrm{~K}$. Measured with $U_{b}-0.5 \mathrm{~V}, I_{t} 0.1 \mathrm{nA}$.
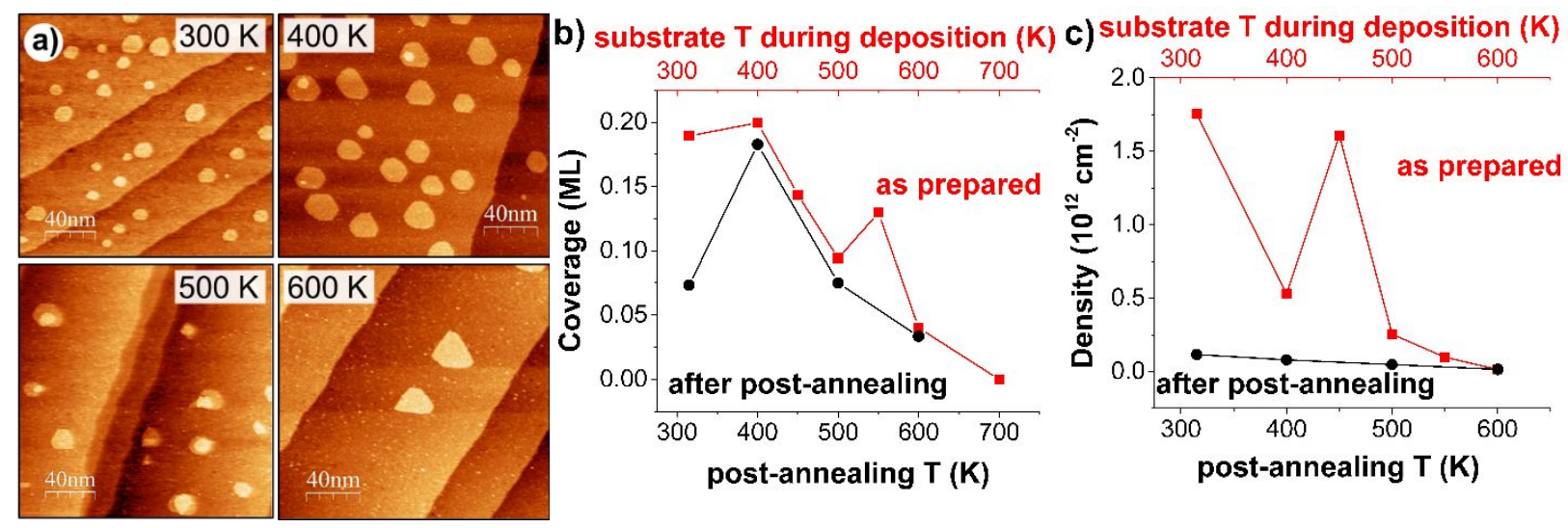

Figure 7. a) STM topography images of $0.20 \mathrm{ML}$ Rh deposited on Pt(111) kept at $300-600 \mathrm{~K}$ and subsequently flash-annealed to $700 \mathrm{~K}$ (deposition temperature indicated in the corner). $U_{b}-0.5 \mathrm{~V}$, $I_{t} 0.1 \mathrm{nA} . \mathrm{b}$ ) and c) show coverage and island density of as-prepared (red, square) and surfaces (black, circle), after flash-annealing to $700 \mathrm{~K}$, as extracted from STM images in Figure 6 and Figure 7a.

Some more observations should be emphasized. The maximum Rh coverage on steps was found at $450 \mathrm{~K}$. Above $550 \mathrm{~K}$, no overlayers at the steps can be seen, most probably due to subsurface 
diffusion of Rh through step channels. At 450 and $500 \mathrm{~K}$ no significant subsurface diffusion of Rh into Pt on terraces occurs, based on observation of small nuclei trapped on the surface between Rh clusters (Figure S3), which disappear above $550 \mathrm{~K}$.

Finally, to compare morphologies obtained at elevated growth temperatures with those obtained using post-annealing (Figure 3), a selection of the surfaces imaged in Figure 6 were flash-annealed to $700 \mathrm{~K}$ (Figure 7). In general, for depositions originally at $300-600 \mathrm{~K}$, with subsequent flash annealing to $700 \mathrm{~K}$ the shape of all islands changed to hexagon-like. The islands varied in size around $10-30 \mathrm{~nm}$. The most well-defined hexagons with also a narrow size distribution were obtained for surfaces prepared at $400 \mathrm{~K}$ and flash annealed to $700 \mathrm{~K}$. As expected for postannealing, island density decreased substantially with the most significant change evident for samples post-annealed after deposition at $300-400 \mathrm{~K}$ (Figure 7c). Preparation of surfaces above $450 \mathrm{~K}$ results in a significantly lower Rh coverage ( $75 \%$ of that at RT, and dropping down $(<50 \%)$ as the deposition temperature increases further), which implies that adatoms have less time to form (or join) a critical nucleus before diffusion subsurface occurs. This effect is expected to be particularly pronounced at the low evaporation rates $(0.05 \mathrm{ML} / \mathrm{min})$ employed in this study.

\section{Comparison with post-annealed Pt/Pt(111)}

To compare the morphology of post-annealed $\mathrm{Rh} / \mathrm{Pt}(111)$ and post-annealed $\mathrm{Pt} / \mathrm{Pt}(111)$ we deposited 0.38 ML Pt on Pt(111) at $300 \mathrm{~K}$ and flash-annealed at $450-750 \mathrm{~K}$ (Figure 8). 

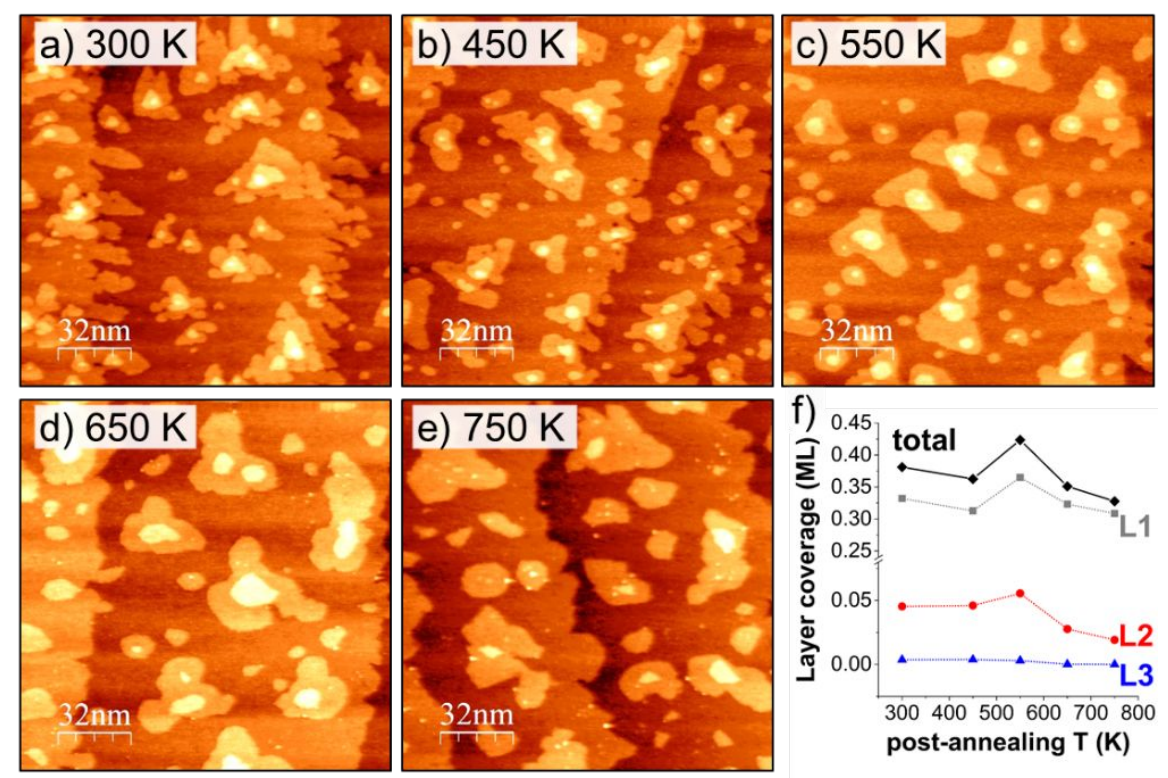

Figure 8. a - e) STM topography images of $0.38 \mathrm{ML}$ Pt deposited on $\mathrm{Pt}(111)$ at $300 \mathrm{~K}$ and postannealed to $450-750 \mathrm{~K}$ for $5 \mathrm{~min}$. Image size $160 \times 160 \mathrm{~nm}^{2}, U_{b}-0.5 \mathrm{~V}, I_{t} 0.1 \mathrm{nA}$. f) Coverage of layers 1 - 3 obtained from STM images in a - e).

Consistent with literature, ${ }^{14}$ at $300 \mathrm{~K}$ Pt grows into 3D triangle-like structures with all three layers pointing in the same direction. Similarly to $\mathrm{Rh} / \mathrm{Pt}(111)$, step-wise annealing to $750 \mathrm{~K}$ causes island growth, resulting in a steady decrease in cluster density. Notably the third layer, formed at $300 \mathrm{~K}$, contributing only to ca. $1 \%$ of the total coverage, remains on the surface up to $550 \mathrm{~K}$ and vanishes after annealing at $650 \mathrm{~K}$. Similar to the evolution of the layers for $0.50 \mathrm{ML} \mathrm{Rh} / \mathrm{Pt}(111)$ in Figure 3, post-annealing of $\mathrm{Pt} / \mathrm{Pt}(111)$ to $550 \mathrm{~K}$ results in a slight growth of the second layer (Figure 8f). More interesting, the first layer exhibits a more pronounced increase in the coverage after annealing at $550 \mathrm{~K}$. Thus, summarizing the contributions from all three layers, at $550 \mathrm{~K}$ the coverage of $0.42 \mathrm{ML}$ is $10 \%$ higher than the starting coverage, and $17 \%$ higher than the coverage at $450 \mathrm{~K}$. Subsequent annealing to higher temperatures causes a decrease in coverage from 0.42 to $0.33 \mathrm{ML}(-13 \%$ relative to starting coverage). The increase in total coverage for both $\mathrm{Rh} / \mathrm{Pt}(111)$ and $\mathrm{Pt} / \mathrm{Pt}(111)$, Figure $3 \mathrm{~b}$ and Figure $8 \mathrm{f}$, respectively, is attributed to diffusion of Pt atoms into 
existing Rh and Pt islands. Annealing to higher temperatures allows atoms from the second or third layer to diffuse down into the first layer, and furthermore into the $\operatorname{Pt}(111)$ crystal.

\section{Roadmap for preparing $\operatorname{RhPt} / \operatorname{Pt}(111)$ surfaces}

The deposition and annealing of $\mathrm{Rh}$ on $\mathrm{Pt}(111)$ employing various experimental conditions gave rise to a variety of island morphologies as summarized in the roadmap, Figure 9. Starting from deposition at room temperature, the major effects of post-annealing are cluster growth, shape transformation from triangular to hexagonal, and intermixing of $\mathrm{Rh}$ and $\mathrm{Pt}$ at steps and terraces (Figure 9, middle panel). As illustrated in Figure 2 and Figure S2, annealing of RT-deposited samples above $550 \mathrm{~K}$ is sufficient for formation of hexagon-shaped structures. In contrast, such hexagon-shaped islands are never directly obtained by high temperature deposition of Rh on Pt kept at $550-600 \mathrm{~K}$, but only via subsequent post-annealing (Figure 7). We also find that room temperature deposition combined with post-annealing yields more stable islands, which loose less than $20 \%$ of the Rh signal at $700 \mathrm{~K}$ as indicated by XPS data. This is in striking contrast to hightemperature deposition, where at $700 \mathrm{~K}$ no Rh overlayer was found at the surface, and already at $550 \mathrm{~K}$ the island coverage dropped by $50 \%$ (Figure $3 \mathrm{~b}$ and Figure S4). Furthermore, morphologically the post-annealed samples are quite stable (at least $3 \mathrm{~h}$ at $550-600 \mathrm{~K}$ ) in UHV, which is a prerequisite for systematic studies. 

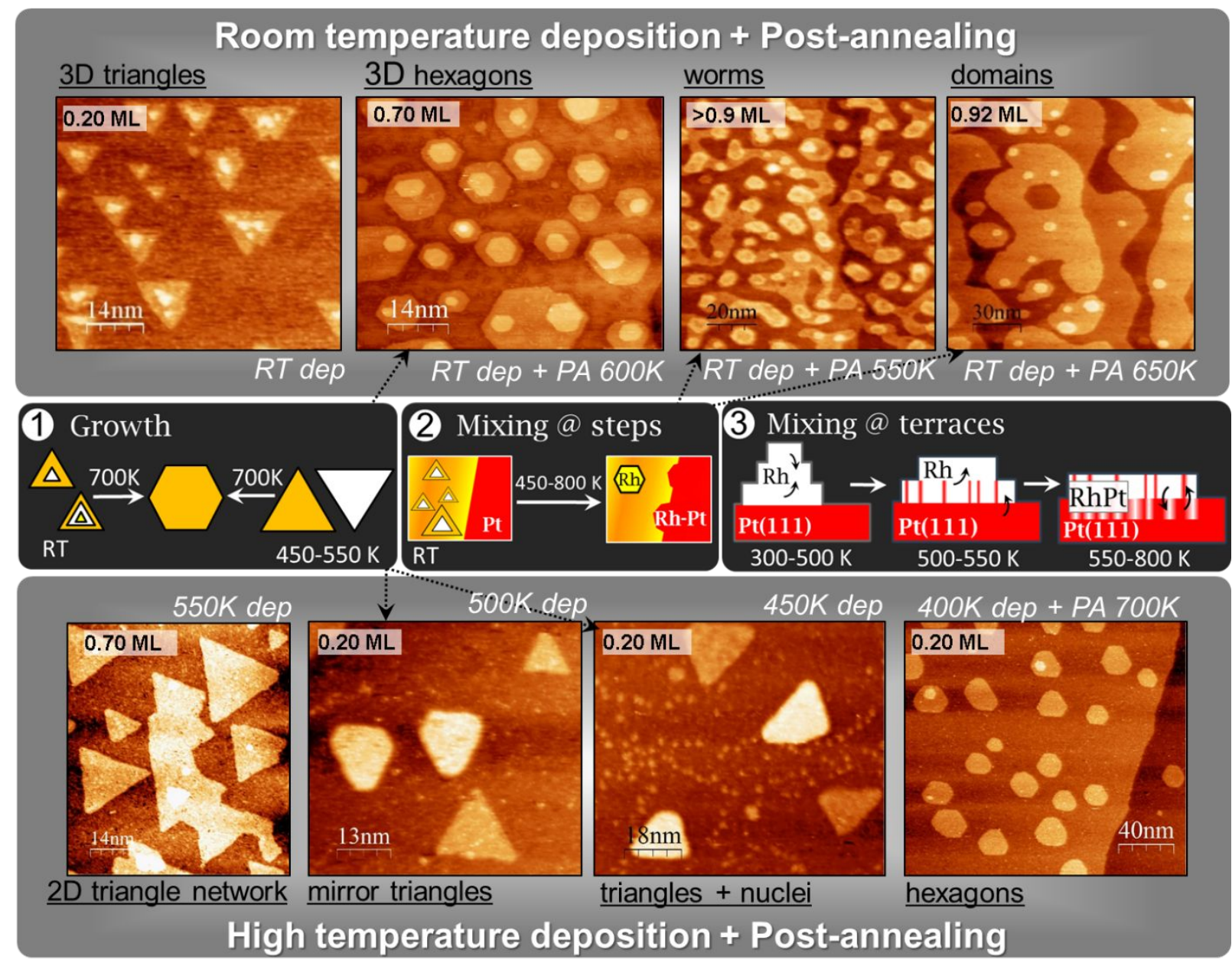

Figure 9. Roadmap for achieving distinct alloyed RhPt morphologies on $\mathrm{Pt}(111)$ using postannealing (top panel) and deposition at higher temperatures (bottom panel). Structures like 3D triangles and hexagons, worms, domains, 2D networks, opposing triangles, small nuclei, and 2D hexagons can be prepared at the indicated conditions (white font). The starting $\mathrm{Rh}$ coverage as estimated by STM is indicated for each surface.

For mimicking a working Pt-Rh alloyed catalyst it is crucial that the two elements form a solid solution in the model material, specifically, that a surface alloy $\mathrm{RhPt} / \mathrm{Pt}(111)$ exists. We found that post-annealing to $600 \mathrm{~K}$ or deposition above $550 \mathrm{~K}$ are needed to induce such mixing of Pt and Rh. The mixing takes place within the islands, on terraces and step edges (Figure 9, middle panel). 
In the context of alloying within the island, it is important to mention that Pt detachment from the Pt step edges and self-diffusion to reach an adjacent $\mathrm{Rh}$ island can occur within the temperature range studied. In particular, it could explain a small increase in STM-based coverage at $550 \mathrm{~K}$ (Figure 3 and Figure 8). In contrast, data for the post-annealing to higher temperatures does not support this, where no additional coverage due to Pt enrichment arriving from the step edges was observed. The presence of islands on top of the step edges, complete islands merged with steps and denuded areas adjacent to the edges was interpreted as tendency to mix with the step without additional Pt laterally diffusing from the step.

Near surface alloy (NSA) in which Rh island would reside underneath the first layer of Pt was suggested in the literature and at lower temperature it can be excluded based on 3-dimensional growth of islands. Formation of NSA may be more likely at elevated temperatures, where 2-d growth is observed, however our preliminary STM imaging with chemical contrast does not support this hypothesis. STM image obtained after adsorbate-induced tip switching (Figure S5), similarly to Varga et al., ${ }^{13}$ shows that single layer with uniform topography in fact features a complex surface alloy structure when imaged with chemical contrast.

Obtaining alloying of $\mathrm{Pt}$ and $\mathrm{Rh}$ in these nanostructures upon gentle annealing is in line with what is known for PtRh-based nanoparticles in supported catalysts, and in consensus with predictions of Ruban et al. for Pt-Rh surfaces. ${ }^{12}$ With reference to this work, we expect that $\mathrm{Rh}$ mixes with $\mathrm{Pt}$ as $\mathrm{RhPt} / \mathrm{Pt}(111)$.

\section{Conclusions}


Rhodium evaporated onto $\operatorname{Pt}(111)$ surfaces was shown to acquire a number of different morphologies, which were controlled via the preparation parameters - coverage, deposition rate, substrate temperature during deposition, and post-annealing. Structures that resemble triangles, triangular networks, worms, hexagons, and domains with hexagon vacancies were obtained. The access to a large number of island shapes and compositions is particularly useful for establishing structure-performance relationships. The observed morphology and (Rh island - Pt surface) mixing is qualitatively similar to the archetypical system of Pt homoepitaxially grown on $\mathrm{Pt}(111)$ $14,20,26$ and heteroepitaxial examples of $\mathrm{Ru} / \mathrm{Pt}(111),{ }^{17-18}$ and is governed by a combination of interand intra-layer diffusion barriers.

For future studies of intermediate-temperature ammonia oxidation, we developed a recipe employing post-annealing and high temperature deposition, which resulted in well-mixed RhPt surfaces with either triangular or hexagonal island shapes. The optimal window for $\mathrm{Rh}$ and $\mathrm{Pt}$ mixing is found around $550 \pm 50 \mathrm{~K}$, which allows $\mathrm{Rh}$ diffusion into the top layers of the $\operatorname{Pt}(111)$ crystal, and Pt diffusion into Rh islands. The post-annealed surfaces exhibited very good temperature stability and maintained their initial morphology for at least $3 \mathrm{~h}$ without evidence of sintering or diffusion subsurface at $550-600 \mathrm{~K}$.

In terms of morphologies and degree of mixing, the distinct nano-structuring obtained by manipulating the steps in the preparation routes is expected to result in marked differences in catalytic activity and selectivity. Hence, we foresee these surfaces to become particularly useful in systematic studies to optimize Pt-Rh alloying for catalysis.

\section{ASSOCIATED CONTENT}


Supporting Information. Detailed description of the experimental setup ReactorSTM, additional STM images and XPS spectra are included in the online supporting information. The following files are available free of charge.

Supporting information (PDF).

\section{AUTHOR INFORMATION}

Corresponding Author

Anja O. Sjåstad, a.o.sjastad@kjemi.uio.no

\section{Author Contributions}

The manuscript was written through contributions of all authors. All authors have given approval to the final version of the manuscript. $¥$ These authors contributed equally.

\section{ACKNOWLEDGMENTS}

The authors appreciate experimental support from PhD candidate Mahesh Prabhu at Leiden University during XPS measurements. O.I. and Z.J. acknowledge respectively support by the industrial Catalysis Science and Innovation Centre (iCSI) and the ASCAT-project, which receives financial support from the Research Council of Norway (contract No. 237922 and 247753).

\section{REFERENCES}

1. Hagen, J., Industrial Catalysis: A Practical Approach. Wiley-VCH Verlag GmbH \& Co. KGaA: Weinheim, Germany, 2015.

2. Skalska, K.; Miller, J. S.; Ledakowicz, S., Trends in Nox Abatement: A Review. Sci. Total Environ. 2010, 408, 3976-3989. 
3. Lietti, L.; Alemany, J. L.; Forzatti, P.; Busca, G.; Ramis, G.; Giamello, E.; Bregani, F., Reactivity of $\mathrm{V}_{2} \mathrm{O}_{5}-\mathrm{WO}_{3} / \mathrm{TiO}_{2}$ Catalysts in the Selective Catalytic Reduction of Nitric Oxide by Ammonia. Catal. Today 1996, 29, 143-148.

4. Guan, B.; Zhan, R.; Lin, H.; Huang, Z., Review of State of the Art Technologies of Selective Catalytic Reduction of Nox from Diesel Engine Exhaust. Appl. Therm. Eng. 2014, 66, 395-414.

5. Jansson, J., Vanadia-Based Catalysts for Mobile Scr. In Urea-Scr Technology for Denox after Treatment of Diesel Exhausts, Nova, I.; Tronconi, E., Eds. Springer: New York, 2014; pp 65-96.

6. Johnson, T. V., Review of Selective Catalytic Reduction (Scr) and Related Technologies for Mobile Applications. In Urea-Scr Technology for Denox after Treatment of Diesel Exhausts, Nova, I.; Tronconi, E., Eds. Springer: New York, 2014; pp 3-31.

7. Jabłońska, M.; Palkovits, R., Copper Based Catalysts for the Selective Ammonia Oxidation into Nitrogen and Water Vapour-Recent Trends and Open Challenges. Appl. Catal., B: Env. 2016, 181, 332-351.

8. Dhak, P. M., M.M.; Bundli, S.A.; Jensen, M.; Zacharaki, E.; Fjellvåg, H.; Menon, M.; Skau, K.I.; Warner, M.; Waller, D.; Sjåstad, A.O., In Monodisperse Bimetallic Pt-Rh and Pt-Pd Nanoparticles for Intermediate Temperature Ammonia Oxidation, 17th Nordic Symposium on Catalysis, Lund, Sweden, June 14-16, 2016; Lund, Sweden, 2016.

9. Massalski, T. B.; Okamoto, H.; Subramanian, P. R.; Kacprzak, L., Binary Alloy Phase Diagrams. 2nd ed.; ASM International: Ohio, USA, 1990. 
10. Steiner, C.; Schönfeld, B.; Portmann, M. J.; Kompatscher, M.; Kostorz, G.; Mazuelas, A.; Metzger, T.; Kohlbrecher, J.; Demé, B., Local Order in Pt-47 At. \% Rh Measured with X-Ray and Neutron Scattering. Phys. Rev. B. 2005, 71, 104204.

11. Park, J. Y.; Zhang, Y.; Grass, M.; Zhang, T.; Somorjai, G. A., Tuning of Catalytic Co Oxidation by Changing Composition of Rh-Pt Bimetallic Nanoparticles. Nano Lett. 2008, 8, 673677.

12. Ruban, A. V.; Skriver, H. L.; Nørskov, J. K., Surface Segregation Energies in TransitionMetal Alloys. Phys. Rev. B. 1999, 59, 15990-16000.

13. Hebenstreit, E. L. D.; Hebenstreit, W.; Schmid, M.; Varga, P., Pt25rh75(111), (110), and (100) Studied by Scanning Tunnelling Microscopy with Chemical Contrast. Surf. Sci. 1999, 441, 441-453.

14. Bott, M.; Michely, T.; Comsa, G., The Homoepitaxial Growth of Pt on Pt(111) Studied with Stm. Surf. Sci. 1992, 272, 161-166.

15. Tsui, F.; Wellman, J.; Uher, C.; Clarke, R., Morphology Transition and Layer-by-Layer Growth of Rh(111). Phys. Rev. Lett. 1996, 76, 3164-3167.

16. Freund, J. E.; Edelwirth, M.; Grimminger, J.; Schloderer, R.; Heckl, W. M., Stm-Induced Formation of Ag Islands on $\mathrm{Ag}(111)$. Appl. Phys. A 1998, 66, S787-S790.

17. Bergbreiter, A.; Berko, A.; Erne, P. M.; Hoster, H. E.; Behm, R. J., On the Origin of Ru Bilayer Island Growth on Pt(111). Vacuum 2009, 84, 13-18.

18. Berkó, A.; Bergbreiter, A.; Hoster, H. E.; Behm, R. J., From Bilayer to Monolayer Growth: Temperature Effects in the Growth of Ru on Pt(111). Surf. Sci. 2009, 603, 2556-2563. 
19. Bott, M.; Hohage, M.; Michely, T.; Comsa, G., Pt(111) Reconstruction Induced by Enhanced Pt Gas-Phase Chemical Potential. Phys. Rev. Lett. 1993, 70, 1489-1492.

20. Kalff, M.; Comsa, G.; Michely, T., How Sensitive Is Epitaxial Growth to Adsorbates? Phys. Rev. Lett. 1998, 81, 1255-1258.

21. Bassett, D. W.; Webber, P. R., Diffusion of Single Adatoms of Platinum, Iridium and Gold on Platinum Surfaces. Surf. Sci. 1978, 70, 520-531.

22. Jacobsen, J.; Jacobsen, K. W.; Nørskov, J. K., Simulations of Homoepitaxial Growth of Pt(111): Island Shapes and the Growth Mode. Scanning Microsc. 1998, 12, 81-91.

23. Lundgren, E.; Schmid, M.; Leonardelli, G.; Hammerschmid, A.; Stanka, B.; Varga, P., On the Role of Kinks and Strain in Heteroepitaxial Growth: An Stm Study. Surf. Rev. Lett. 2000, 07, 673-677.

24. Lundgren, E.; Stanka, B.; Leonardelli, G.; Schmid, M.; Varga, P., Interlayer Diffusion of Adatoms: A Scanning-Tunneling Microscopy Study. Phys. Rev. Lett. 1999, 82, 5068-5071.

25. Jacobsen, J.; Jacobsen, K. W.; Nørskov, J. K., Island Shapes in Homoepitaxial Growth of Pt(111). Surf. Sci. 1996, 359, 37-44.

26. Michely, T.; Hohage, M.; Bott, M.; Comsa, G., Inversion of Growth Speed Anisotropy in Two Dimensions. Phys. Rev. Lett. 1993, 70, 3943-3946.

27. Herbschleb, C. T.; van der Tuijn, P. C.; Roobol, S. B.; Navarro, V.; Bakker, J. W.; Liu, Q.; Stoltz, D.; Cañas-Ventura, M. E.; Verdoes, G.; van Spronsen, M. A., et al., The Reactorstm: Atomically Resolved Scanning Tunneling Microscopy under High-Pressure, High-Temperature Catalytic Reaction Conditions. Rev. Sci. Instrum. 2014, 85, 083703. 
28. Least-Squares Curve Fitting Program Winspec, 2.09; LISE laboratory of the Facultes Universitaires Notre-Dame de la Paix: Namur, Belgium, 2001.

29. Rost, M. J.; Crama, L.; Schakel, P.; van Tol, E.; van Velzen-Williams, G. B. E. M.; Overgauw, C. F.; ter Horst, H.; Dekker, H.; Okhuijsen, B.; Seynen, M., et al., Scanning Probe Microscopes Go Video Rate and Beyond. Rev. Sci. Instrum. 2005, 76, 053710.

30. Leiden Probe Microscopy. http://www.leidenprobemicroscopy.com/ (accessed October 3, 2018).

31. Nečas, D.; Klapetek, P., Gwyddion: An Open-Source Software for Spm Data Analysis. Open Phys. 2012, 10, 181-188.

32. Assumpção, M. H. M. T.; Piasentin, R. M.; Hammer, P.; De Souza, R. F. B.; Buzzo, G. S.; Santos, M. C.; Spinacé, E. V.; Neto, A. O.; Silva, J. C. M., Oxidation of Ammonia Using Ptrh/C Electrocatalysts: Fuel Cell and Electrochemical Evaluation. Appl. Catal., B: Env. 2015, 174-175, $136-144$.

33. Bergene, E.; Tronstad, O.; Holmen, A., Surface Areas of Pt-Rh Catalyst Gauzes Used for Ammonia Oxidation. J. Catal. 1996, 160, 141-147.

34. Contour, J. P.; Mouvier, G.; Hoogewys, M.; Leclere, C., X-Ray Photoelectron Spectroscopy and Electron Microscopy of Pt-Rh Gauzes Used for Catalytic Oxidation of Ammonia. J. Catal. $1977,48,217-228$.

35. Cowans, B. A.; Jurman, K. A.; Delgass, W. N.; Li, Y. Z.; Reifenberger, R.; Koch, T. A., Scanning Tunneling Microscopy of Platinum-Rhodium Gauze Hcn Catalysts. J. Catal. 1990, 125, 501-513. 
36. Fierro, J. L. G.; Palacios, J. M.; Tomas, F., An Analytical Sem and Xps Study of PlatinumRhodium Gauzes Used in High Pressure Ammonia Burners. Surf. Interface Anal. 1988, 13, 25-32. 


\section{TOC Graphic}

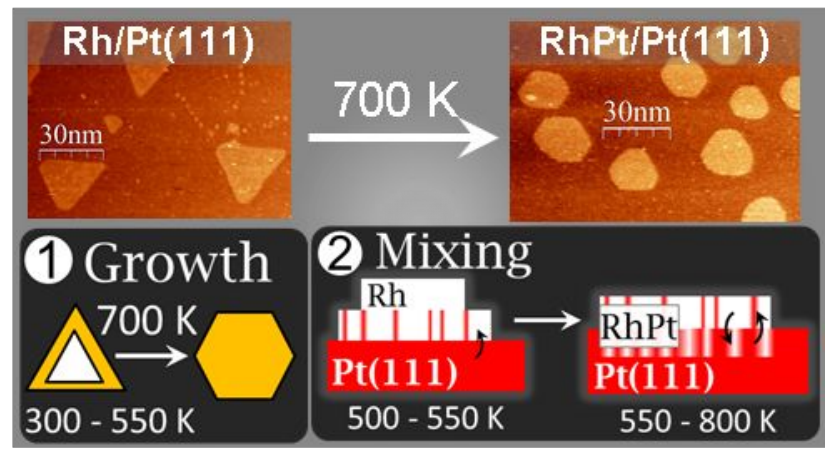

